\title{
Antropologia Econômica
}

Julien Duval ${ }^{2}$

Eu tentarei dar um panorama do livro Anthropologie Économique, publicado em francês em novembro de 2017. Minha exposição vai tratar essencialmente das grandes ideias desenvolvidas por Pierre Bourdieu nesta obra. Contudo, antes disso, é necessário dizer algumas palavras sobre a origem deste livro e o modo pelo qual ele foi elaborado.

Anthropologie Économique se inscreve numa série de publicaçôes dos cursos de Pierre Bourdieu no Collège de France. De 1982 até sua aposentadoria em 2001, Bourdieu lecionou nessa instituição que é muito antiga (data do século XVI), muito prestigiada, mas também muito peculiar no âmbito do sistema de ensino francês. O Collège de France não é uma universidade, não fornece diploma e nenhum estudante precisa se inscrever: todos podem ir e ouvir os cursos que são oferecidos. Essa instituição conta com mais ou menos cinquenta professores que são pesquisadores extremamente reconhecidos e representam as diferentes áreas do conhecimento: matemática, física, biologia, história, literatura, etc. Cada um desses professores ministra, a cada ano, uma pequena quantidade de aulas (fala-se em "aulas magistrais") nas quais serão apresentadas suas próprias pesquisas em andamento. Bourdieu respeitava as regras dessa instituição e ministrava, portanto, a cada ano, por volta de dez aulas bem magistrais

\footnotetext{
Tradução de Jéssica Ronconi Fernandes e revisão técnica de Carolina Pulici. Conferência realizada em 24/05/20I8 na Escola de Filosofia, Letras e Ciências Humanas da Universidade Federal de São Paulo, em Guarulhos, por ocasião da publicação do livro póstumo de Bourdieu, Anthropologie Économique. Cours au Collège de France, 1992-1993 (Raisons d'agir/Seuil, 2017), cuja edição foi realizada por Julien Duval e Patrick Champagne. Duval foi também co-resposável pela edição dos cursos de Bourdieu publicados em Sociologie Générale. Cours au Collège de France, 1981-1983, Volume I (Raisons d’agir/Seuil, 2015) e Sociologie Générale. Cours au Collège de France, 1983-1986, Volume 2 (Raisons d'agir/Seuil, 2016).

2 Diretor de pesquisas no CNRS (França) e autor de Critique de la raison journalistique. Les Transformations de la presse économique en France
}

$(\infty)$ EY
Direito autoral e licença de uso: Este artigo está licenciado sob uma Licença Creative Commons. Com essa licença você pode compartilhar, adaptar, para qualquer fim, desde que atribua a autoria da obra, forneça um link para a licença, e indicar se foram feitas alterações. 
perante um público em grande parte anônimo. No entanto, enquanto outros professores do Collège de France liam um curso previamente escrito, Bourdieu encorajava o público (numeroso) que vinha assisti-lo a colocar questóes (por escrito), e se permitia fazer digressóes e improvisaçóes, como normalmente ocorria em seus seminários de pesquisa em outras instituiçôes (na École des Hautes Études en Sciences Sociales particularmente) desde os anos 1960. Desse modo, seus cursos no Collège de France davam lugar à desordem e às hesitaçóes que Bourdieu considerava inerentes ao trabalho de pesquisa. Eles se distinguem dos seus artigos e livros, pois nos cursos Bourdieu se exprimia mais livremente e, num certo sentido, expunha seu trabalho de modo mais acessível, mais pedagógico e mais vivo.

Esta é uma das razóes que levaram a Raisons d'agir (a pequena editora que Bourdieu havia criado em 1997, inicialmente para publicar as obras de intervenção) e a Seuil (editora na qual era publicada a maior parte de seus livros desde a sua saída da Minuit, por volta de 1990) a lançar a edição dos cursos ministrados por Bourdieu no Collège de France durante vinte anos. A empreitada começou em 2012 com a publicação de Sobre o Estado ${ }^{3}$, que corresponde aos cursos oferecidos entre 1989 e 1992; continuou em 2013 com a publicação de Manet. Une Révolution symbolique 4 , que corresponde aos cursos ministrados em 1997 e 1999; e, ainda, com a publicação de dois volumes intitulados Sociologie Générale , que representam um total de 2000 páginas que reúnem os cinco primeiros anos do ensino de Bourdieu no Collège de France, entre 1982 e 1986.

O objetivo desta série de livros é publicar a íntegra dos cursos, ou seja, não as anotaçôes de cursos de Bourdieu, mas a transcrição integral dos mesmos. Esses cursos haviam sido registrados em fitas cassetes pelas pessoas que os assistiam e depois foram transcritos para a edição dos volumes. $\mathrm{O}$ texto transcrito foi ligeiramente reescrito para que sua leitura ficasse mais fluida, tendo-se acrescentado um "aparelho crítico", principalmente as notas de artigos ou livros aos quais Bourdieu faz referência em seus cursos, ou ainda as publicaçóes em que ele desenvolveu pontos rapidamente

\footnotetext{
3 BOURDIEU, Pierre. Sobre o Estado. São Paulo: Companhia das Letras, 2014.

4 BOURDIEU, Pierre. Manet. Une Révolution Symbolique. Paris: Raisons d'agir/Seuil, 2013.

5 Cf. nota I.
} 
evocados. As notas também fornecem as precisões necessárias à compreensão de certas alusôes que ele faz a pessoas ou fatos contemporâneos aos cursos.

Anthropologie Économique corresponde à integralidade do curso que Pierre Bourdieu lecionou ao longo do ano universitário 1992-1993 sob o título de "Os fundamentos sociais da ação econômica". Trata-se do $11^{\circ}$ ano de ensino de Bourdieu no Collège de France, dando sequência ao curso de sociologia geral e ao curso sobre o Estado que se estenderam, cada um, por cinco anos ${ }^{6}$. Em 1992-1993, ele não inicia um novo ciclo ${ }^{7}$, mas opta por oferecer uma formaçáo sobre a economia sem o intuito de prolongá-la nos anos seguintes. Seu objetivo é propor uma discussão crítica da ciência econômica e, mais exatamente, da corrente "neoclássica" que, ao menos na França, sempre foi dominante na disciplina econômica e sempre manteve, com intensidade variada segundo as épocas, as correntes "críticas" - como as ligadas ao marxismo - em posiçóes bastante marginais. A corrente "neoclássica” se desenvolve no fim do século XIX, mas, como seu próprio nome indica, ela se inscreve na continuação da "economia clássica" nascida na Grã-Bretanha nos séculos XVIII e XIX, notadamente com Adam Smith e Ricardo. Ela se baseia na teoria da ação racional: o modelo do homo economicus postula que os agentes econômicos se comportam de forma racional buscando maximizar seus interesses materiais individuais. Com frequência, ela leva a conclusóes políticas "liberais" segundo as quais o mercado e a livre concorrência são formas ideais de organização econômica.

Ao propor uma discussão crítica da economia neoclássica, Pierre Bourdieu se propóe a um exercício que é quase um ritual na sociologia: como demonstra o exemplo dos grandes fundadores desta disciplina (Karl Marx, Émile Durkheim, mas também Max Weber), a sociologia é em parte construída numa relação de oposição à ciência econômica clássica e neoclássica. Ao longo de todo o século XX, e ainda hoje, as críticas feitas pelos sociólogos à ciência econômica dominante foram numerosas. A originalidade da discussão proposta por Bourdieu reside no fato de ele considerar

\footnotetext{
O volume Sobre o Estado corresponde aos três últimos anos deste curso.

7 Isso talvez tenha se devido a circunstâncias bem materiais: Bourdieu possivelmente antecipava os trabalhos de reforma que começariam no Collège de France e que o obrigariam nos anos seguintes a deslocar - mas também a dividir - seu ensino em cidades diferentes, na França e em países fronteiriços.
} 
que muitos sociólogos, ao criticarem os economistas, ocupam-se menos da ciência econômica tal como ela é do que de uma imagem grosseira e caricatural da mesma. Consequentemente, eles errariam com frequência o alvo por não se darem conta de que a economia é hoje objetivamente uma disciplina muito sofisticada. Ela produz em si mesma formas de autocrítica que, mesmo parciais, a protegem dos ataques externos dos quais ela pode vir a ser objeto. Bourdieu afirma que é muito difícil formular críticas que já não tenham sido feitas pelos economistas. Por essa razão, ele compara a economia à "hidra de Lerna”, criatura da mitologia grega invencível cujas cabeças ressurgem a cada vez que são cortadas. Com base nessa análise, Bourdieu opta pela seguinte estratégia: em sua discussão crítica da economia, ele se apoiará nos trabalhos de economistas.

Pode-se dizer, portanto, que o curso procura desenvolver uma crítica da economia apoiada nas próprias críticas formuladas por certos economistas a respeito de sua disciplina. Com efeito, Bourdieu se dedica notadamente a identificar os pressupostos filosóficos que a economia neoclássica mobiliza, o mais das vezes sem o dizer, para então apontar seus limites. O mercado não é uma criaçáo natural e o homem capitalista não é um sujeito atemporal que estabelece conscientemente os fins e calcula, com a precisão de uma máquina, os melhores meios de atingi-los. O homo economicus é antes de tudo uma construção dos economistas e, como sua própria disciplina, ele só pôde passar a existir ao final de um processo histórico que constituiu um "campo econômico" suficientemente autônomo. Bourdieu poderia fazer sua a observação de Marcel Mauss em Ensaio sobre a dádiva, segundo a qual "foram nossas sociedades ocidentais que, muito recentemente, fizeram do homem um 'animal econômico” e, como Mauss, ele poderia acrescentar que "nem todos somos ainda seres desse gênero 8 ": o homo economicus é, no seu modo de ver, apenas um limite nunca totalmente alcançado na prática. Nesse sentido, o objetivo de Bourdieu não se reduz a uma crítica da ciência econômica: trata-se também de substituir os instrumentos que ela utiliza por outros, segundo ele mais poderosos e

8 MAUSS, Marcel. «Essai sur le don ", Sociologie et anthropologie, Paris, PUF, "Quadrige », 1997, p. 27I. [ed. bras.: Ensaio sobre a dádiva: forma e razão da troca nas sociedades arcaicas. In: Sociologia e antropologia. São Paulo: Cosac \& Naif, 2003, p. 307]. 
mais bem fundamentados, oriundos da teoria sociológica que ele elaborou ao longo de toda sua obra. De fato, um dos objetivos do curso é também propor uma análise da vida econômica baseada nos conceitos de campo e de habitus, ao invés da noção habitual de "mercado" e da teoria da ação racional mobilizadas pelos economistas.

Antes de entrar mais detalhadamente na proposta do curso, uma última observação preliminar pode dar a dimensão do interesse que ele pode apresentar. Uma das tarefas que Bourdieu se coloca nessa formação do começo dos anos 1990 consiste em reunir, sintetizar, mas, também, provavelmente, dar visibilidade ao conjunto da reflexão que ele desenvolveu, ao longo de toda a sua obra, a respeito da economia. Ao menos na França, Bourdieu não era realmente visto pelos outros sociólogos, e muito menos pelo público "cultivado", como um sociólogo da economia. É primeiro e sobretudo como um sociólogo do sistema educacional e das práticas culturais que ele era conhecido; seus livros mais lidos foram, certamente, $O s$ Herdeiros $^{9}, A$ Reprodução ${ }^{10}$ e $A$ Distinção ${ }^{11}$. Contudo, desde muito cedo ele havia começado a esboçar uma sociologia econômica. Essa abordagem era central nas empreitadas fundadoras da disciplina por volta de 1900 (na sociologia durkheimiana, em Max Weber, em Pareto etc.), mas caiu em desuso no século XX, antes de conhecer uma espécie de renovação a partir dos anos 1980, nos Estados Unidos e, em um segundo momento, na Europa.

Desde suas primeiras pesquisas na Argélia, no final dos anos 1950, Bourdieu se interrogava sobre as questóes econômicas (o desemprego, a introdução de práticas capitalistas numa sociedade tradicional) e colocava em questão as análises oriundas da economia clássica. De volta à França, ele continuava a trabalhar, paralelamente às suas pesquisas sobre educação e cultura, com questôes como o acesso ao crédito e as relaçóes entre os bancos e seus clientes ${ }^{12}$, ou a distribuição do crescimento econômico na

9 BOURDIEU, Pierre; PASSERON, Jean-Claude. Os Herdeiros. Os estudantes e a cultura. Florianópolis : Editora da UFSC, 2014.

10 BOURDIEU, Pierre; Passeron, Jean-Claude. A Reprodução. Elementos para uma teoria do sistema de ensino. Petrópolis: Vozes, 2008.

I BOURDIEU, Pierre. A Distinção. Crítica social do julgamento. São Paulo: Edusp/Porto Alegre: Zouk, 2007.

I2 BOLTANSKI, Luc; CHAMBOREDON, Jean-Claude. "La Banque et sa clientèle”, relatório mimeografado do Centro de sociologia europeia, 1963. 
França nos anos $1960^{13}$. Ao mesmo tempo, ou pouco depois, ele aprimorava, com base em suas pesquisas na Argélia, a análise do dom. Nos anos 1970, ele passa a trabalhar mais intensamente sobre o que ele chama de "os campos de produção cultural” (a literatura, a arte, a ciência...), nos quais ele vê os ressurgimentos da economia pré-capitalista no âmago das sociedades capitalistas. Seu grande livro dos anos 1970, A Distinção, que propóe uma análise não somente das práticas culturais, mas do consumo de um modo geral e dos modos de vida, desenvolve um modelo de compreensão do consumo que concorre com aquele que os economistas defendem. Ele também realiza nos anos 1970, com Monique de Saint Martin, uma pesquisa sobre o "patronato" e, nos anos 1980, começa uma pesquisa sobre a casa individual.

Em seu curso no Collège de France, Bourdieu sistematiza, portanto, a reflexão sobre a economia desenvolvida ao longo de todas essas pesquisas. No começo dos anos 1990 ele tinha por volta de sessenta anos, o que o predispunha a se debruçar sobre o conjunto do seu trabalho. Mas o contexto intelectual e político também deve ter sido favorável a essa tarefa. Desde o fim dos anos 1970, a economia neoclássica voltou a ganhar espaço e, com ela, a teoria da ação racional. A atribuição, alguns meses antes do começo do curso, do Prêmio Nobel de economia a Gary Becker constitui, a esse respeito, um símbolo: ela consagra um pesquisador da mesma geração de Bourdieu que também propôs uma empreitada muito ambiciosa em ciências humanas. A orientação deste trabalho era, contudo, bem diferente, uma vez que consistia em uma espécie de transposição generalizada do modelo do homo economicus ao conjunto dos comportamentos humanos (as escolhas matrimoniais, familiares, escolares, etc.)

O retorno do homo economicus a partir dos anos 1970 não é independente das transformaçóes políticas da época. Alguns representantes da "nova economia clássica" que se consolida em Chicago participaram, aliás, muito diretamente das "revoluçóes neoliberais" realizadas a partir da metade dos anos 1970: no Chile, nos Estados Unidos com Ronald Reagen, no Reino Unido com Margaret Thatcher ... No curso, Bourdieu não diz

13 DARRAS, Le Partage des bénéfices, Paris, Minuit, 1966. 
quase nada sobre essas transformações políticas (que não pouparam a França, mesmo que aí tenham tomado formas específicas), mas ele não tinha como não tê-las em mente. No exato momento em que ministra esse curso, Bourdieu publica $A$ miséria do mundo ${ }^{14}$; este é um momento importante no percurso que o leva a intensificar suas intervençôes no debate público ao longo dos anos 1990, e a se aproximar do movimento social e das forças sindicais que, em nível nacional ou europeu, opóem-se ao progresso do neoliberalismo. As implicaçóes políticas das análises que ele desenvolve no curso apareceram explicitamente em muitas de suas intervençóes políticas de meados dos anos 1990. Elas se manifestarão também em certas passagens do seu livro As estruturas sociais da economia ${ }^{15}$, publicado em 2000, que abordarei mais adiante e que prolonga, ao menos sob certos aspectos, o curso de 1992-1993.

A partir de agora buscarei expor as grandes articulaçóes da demonstração de Bourdieu. Meu objetivo é dar um rápido panorama desse curso que, por enquanto, é acessível apenas aos leitores e leitoras francófonos. Devo dizer que tive um interesse pessoal em preparar esta exposição, pois quando editei esse curso com Patrick Champagne, precisei fazer uma leitura linha por linha que não é favorável à apreensão da demonstração de conjunto. É claro que lemos um texto de forma particular quando o editamos, mas me lembro que ao ler Sobre o Estado ou Manet. Une Révolution symbolique, edições das quais eu não havia participado, eu também tive a impressão de perder de vista a estrutura do conjunto. Isso se deve certamente ao fato de que esses cursos constituem, antes de tudo, um discurso oral cujo encanto, numa primeira leitura, está entre parênteses, em digressóes. Entretanto, seus ensinamentos aparentemente muito livres são também muito estruturados quando os examinamos de perto. É a estrutura do conjunto que tentei recuperar ao reler o curso para esta apresentaçáo.

Se a exposição de uma teoria da economia fundada nos conceitos de habitus e de campo me parece ser o cerne do curso, ela só começa de fato na segunda metade e, mesmo, no último terço do curso. Antes disso, Bourdieu avança em uma longuíssima "introdução" (ele mesmo lamenta

I4 BOURDIEU, Pierre. A miséria do mundo. Petrópolis: Vozes, 2008.

15 BOURDIEU, Pierre. As estruturas sociais da economia. Lisboa: Instituto Piaget, 200 I. 
sua extensão) que se apresenta como uma retomada das análises sobre o dom que ele havia publicado anteriormente (notadamente em 1980 em $O$ senso prático $\left.{ }^{16}\right)$. Na realidade, essa "introdução" constitui uma primeira parte do curso que lhe permite colocar os pontos essenciais de sua argumentação. Ela não é apenas uma simples "retomada" das análises sobre o dom, e isso por duas razóes: se Bourdieu repete, nesse curso, coisas que ele já havia escrito sobre o dom, ele também faz ajustes e aprofunda suas análises levando-as a novas direçóes; além disso, sua proposta náo se restringe à análise do dom que é, de certo modo, apenas um ponto de partida.

Se é um ponto de partida, há que se retomar essa análise do dom. O dom é objeto de uma visão primeira, "nativa", que faz dele um ato generoso, desinteressado, sem retorno. Esta visão é a que temos espontaneamente, como agente social, quando damos alguma coisa; é a "experiência vivida" que a análise fenomenológica busca reconstituir. A análise objetivista que Mauss havia empreendido em Ensaio sobre a dádiva (1925) - e que Lévi-Strauss havia radicalizado, de certo modo, nos anos $1950^{17}$ - vai no sentido contrário dessa visão nativa, pois insiste no fato de que não há dom sem contra-dom. Assim, ela rompe com o senso comum e substitui o dom como ato isolado e sem retorno por um "objeto construído" que estabelece a série de trocas nas quais ele se inscreve.

Eu adoto deliberadamente o vocabulário de $O$ ofício do sociólogo ${ }^{18}$ ("ruptura com o senso comum", “objeto construído") para sugerir que Bourdieu era sensível a essa análise objetivista. Ela marca, com efeito, um esforço para superar uma visão nativa e pré-científica que, ao olhar o dom como um ato gratuito, o torna ao mesmo tempo inexplicável. Por outro lado, ele também lamenta que a análise objetivista (ou "estrutural") leve o intelectual a pretender "ter razão contra os agentes nativos". Isso é visto particularmente na abordagem de Claude Lévi-Strauss: os agentes são mistificados, eles acreditam dar livremente quando na verdade seriam joguetes

16 BOURDIEU, Pierre. O senso prático. Petrópolis: Vozes, 2009.

17 MAUSS, Marcel. "Ensaio sobre a dádiva”, op. cit., e LÉVI-STRAUSS Claude. "Introdução à obra de Marcel Mauss". In: MAUSS, Marcel. Sociologia e Antropologia, op. cit.

I8 BOURDIEU, Pierre; CHAMBOREDON, Jean-Claude; PASSERON, Jean-Claude. Ofício do sociólogo. Metodologia da pesquisa na sociologia. Petrópolis: Vozes, 1999. 
das estruturas inconscientes. A teoria segundo a qual o dom implica um contra-dom esquece que, na prática, as coisas não se passam dessa maneira. Na prática, o dom sempre comporta riscos: aquele que recebe, por exemplo, pode recusá-lo ou abster-se de retribuí-lo posteriormente. Os agentes sociais não estáo completamente equivocados: o dom talvez não seja a troca desinteressada que eles celebram, mas ele também não se confunde com o "dar e receber" ao qual a análise objetivista tende a reduzi-lo. Bourdieu acredita que a visão nativa e a análise objetivista são ambas insuficientes. Cada uma delas revela um aspecto de um fenômeno que contém uma "dupla verdade", objetiva e subjetiva. Essas duas verdades devem "ser mantidas juntas" ou, dito de outro modo, deve-se integrar as duas análises, a estrutural e a fenomenológica: o dom não pode ser objetivamente o que diz a análise objetivista, pois ele é vivido como sendo sem retorno. A teoria não é a prática e, na prática, o dom e o contra-dom são separados pelo tempo, permitindo aos participantes da troca ignorar a verdade objetiva da troca.

Os desenvolvimentos que Bourdieu consagra ao que ele chama de "o erro de Lévi-Strauss" me parecem muito importantes no curso, pois eles anunciam a crítica formulada contra a economia. Em certo sentido, Lévi-Strauss raciocina como um economista: ele reduz o dom à lógica do "dar e receber", ou seja, ao único tipo de troca que os economistas consideram. Esta redução articulada pelo autor relaciona duas operações, o dom e o contra-dom, como se fossem quase contemporâneas uma da outra, quando na prática são espaçadas no tempo, de modo que os agentes sociais podem vivenciá-las como se fossem desconectadas uma da outra. Lévi-Strauss comete o erro que Bourdieu qualifica de "escolástico", e que ele também identificará no cerne da teoria econômica neoclássica. $\mathrm{O}$ erro consiste em tomar "as coisas da lógica pela lógica das coisas", isto é, tomar como explicação de um fenômeno o que é apenas uma descrição, colocando no espírito dos agentes sociais o modelo construído pelo cientista. Ele tende também a instantaneizar operaçôes que são separadas, na prática, pelo tempo e que podem, por isso mesmo, ser vividas com certa má-fé: na prática, pode-se agir como se o dom e o contra-dom não tivessem relação e constituíssem, cada um, dois atos generosos.

Ainda que Bourdieu não restabeleça, de modo algum, a visão nativa do dom como um ato desprovido de contrapartida, ele considera que o 
dom é irredutível à lógica do "dar e receber". Ele não é vivido como tal e não pode ser reduzido a uma troca de bens materiais. $\mathrm{O}$ dom produz a gratidão e cria uma obrigação social, ele é o lugar de uma alquimia na qual se troca também, e às vezes antes de tudo, capital simbólico, formas de reconhecimento. Bourdieu vê no dom o produto de uma economia específica, uma "economia dos bens simbólicos", que se distingue da "economia econômica" regida pela lógica do "dar e receber". Ela não implica as mesmas disposiçóes e corresponde a universos sociais nos quais, precisamente, a lógica do cálculo e do dar e receber é censurada: neles a regra é dar, demonstrar desinteresse, e os agentes são socializados e preparados para se comportarem segundo as regras. Bourdieu introduz assim a ideia de que a compreensão de uma economia exige a mobilização dos conceitos de universos sociais e de disposiçóes ou, em outras palavras, de campo e de habitus.

Ele considera, a propósito, que as sociedades pré-capitalistas são o lugar por excelência da economia dos bens simbólicos. É com o desenvolvimento do capitalismo que aparecem e se ampliam os universos sociais fundados sobre a lógica do "dar e receber", e nos quais os agentes sociais começam a calcular explicitamente. Bourdieu tem em mente, é claro, as análises de Max Weber sobre o desenvolvimento do capitalismo no mundo ocidental. Ele já as tinha mobilizado em seus primeiros trabalhos na Argélia, sociedade brutalmente confrontada às lógicas capitalistas devido à colonização francesa. No curso, no entanto, ele dedica mais tempo aos textos de Marcel Mauss. Para descrever o avanço da lógica do dar e receber, Mauss fala de uma "revolução". Esta palavra é familiar a Bourdieu que analisou, notadamente no que diz respeito a Manet, as "revoluçôes simbólicas" associadas à autonomização de campos sociais. A expansão da "economia econômica" é de fato acompanhada do desenvolvimento de novas maneiras de pensar, aquelas que são sistematizadas por uma ciência econômica que Bourdieu considera que seja ao mesmo tempo um fator e um produto da constituição de um "campo econômico" no qual o interesse propriamente econômico deixa de ser reprimido ou dissimulado nas trocas dotadas de grande dimensão simbólica.

Se Bourdieu insiste bastante no fato de que a ordem econômica, normalmente considerada como "natural" pelos economistas, é o produto de 
uma "revolução", ou seja, é uma invenção histórica, ele diz também que essa "revolução" nunca foi total. Com efeito, a lógica do dom e do desinteresse sobrevive em estado de ilha em nossas sociedades capitalistas: os universos da arte, da ciência, mas também o universo das relaçóes domésticas e afetivas continuam sendo, em nossas sociedades, parcialmente refratários à lógica do "dar e receber", que neles permanece tabu, censurada. Mas Bourdieu vai mais longe: mesmo que o mundo econômico pareça ser o mais conforme à lógica do interesse, ele conserva traços das economias précapitalistas e continua sendo o lugar de trocas simbólicas.

Antes de mencionar alguns dos argumentos apresentados por Bourdieu, é necessário evocar suas referências ao Vocabulário das instituiçóes indo-europeias ${ }^{19}$, livro do linguista Émile Benveniste que ele havia publicado em sua coleção e que era citado frequentemente em seus cursos. Bourdieu não deixa de usar os desenvolvimentos de Émile Benveniste sobre a aparição progressiva, e paralela à "revolução" evocada por Mauss, de um vocabulário econômico. Contudo, ele é particularmente atento às observaçóes de Benveniste sobre o fato de que esse vocabulário deriva regularmente de palavras que, em sua acepçáo original, designavam relaçóes sociais próprias da economia dos bens simbólicos. O termo "dívida", por exemplo, designava inicialmente uma dependência política ou moral. Ao menos em francês, ele jamais perdeu totalmente esse sentido, mesmo quando passou a designar paralelamente uma dependência especificamente econômica.

Bourdieu chama atenção para uma sobrevivência fundamental da economia dos bens simbólicos nessa instituição central da vida econômica que é o Estado. Ele a evoca depois de ter lembrado como o dom, nas sociedades tradicionais, visa criar relaçôes de dependência pessoal, e está intimamente ligado às relaçóes de poder por meio da redistribuição dos bens que ele promove. O Estado (ao qual Bourdieu acabara de consagrar cinco anos de curso) revela-se uma instituição dupla. De um lado, é um ator central da "revoluçáo" que tende a reduzir a economia do dom ao estado de "ilha". Seu desenvolvimento participa de um processo de despersonalização e de institucionalização que rompe com as formas de dominação baseadas em

19 BENVENISTE, Émile. O vocabulário das instituições indo-europeias, volume II. São Paulo: Unicamp, 1995. 
relações pessoais e instáveis, típicas das sociedades tradicionais às quais a economia do dom está ligada. Por outro lado, todavia, o Estado perpetua, em escala macrossocial, as lógicas características da economia de bens simbólicos. A cobrança de impostos e a redistribuição das receitas fiscais, por exemplo, implicam trocas que, como o dom, são inseparavelmente econômicas e políticas, na medida em que asseguram uma circulação de bens materiais ao mesmo tempo em que criam devedores (os grupos sociais beneficiários das transferências) e a legitimidade política.

Ademais, Bourdieu mostra a presença do simbólico em vários outros espaços da vida econômica. Como entender, por exemplo, o mecenato das grandes empresas privadas sem introduzir a noção de capital simbólico? Os modelos que póem em jogo apenas bens materiais e agentes economicamente "racionais" não conseguem dar conta das práticas paternalistas que os empregadores podem continuar a manter em relação aos seus assalariados. Bourdieu também sublinha a importância que os elementos puramente simbólicos desempenham nas negociaçôes entre empregadores e sindicatos ou na fixação dos salários. Ele retoma igualmente as análises desenvolvidas em $A$ Distinçâo: as práticas de consumo nunca são apenas uma questão de utilidade material, mas também de estratégia simbólica. Bourdieu reconhece, certamente, que o "peso do simbólico" varia de acordo com os bens e com os mercados, mas uma economia puramente econômica, livre de qualquer dimensão simbólica, lhe parece algo jamais realizado na prática. Ele poderia fazer sua a fórmula de Mauss segundo a qual o dom é "uma das rochas humanas sobre as quais são construídas nossas sociedades" 20 Ele destaca ainda, no começo de seu curso, que o dom e a generosidade parecem valores humanos universalmente celebrados. Da mesma forma, ele se mostra crítico às teses sobre a "mercantilização" defendidas na tradição marxista ou por George Simmel: a perspectiva de um aniquilamento completo das atividades sociais pelas lógicas "mercantis" parece-lhe da ordem do "mito".

Bourdieu aborda então o cerne de sua argumentação: a crítica da filosofia subentendida na economia neoclássica e a apresentação de uma

20 MAUSS, Marcel. «Ensaio sobre a dádiva », op. cit., pp. 188-189. 
"alternativa teórica" baseada na aplicação do seu sistema de conceitos, e ilustrada pela pesquisa sobre o mercado das casas individuais na França, que ele havia conduzido nos anos 1980.

Ele começa por ressaltar o caráter cartesiano da filosofia implicitamente mobilizada pela economia neoclássica. Ela é antes de tudo dedutivista. E duplamente a-histórica. De fato, por um lado ela apresenta o mercado como uma espécie de produto natural, quando na verdade esse universo que rompeu com a repressão do interesse econômico é um produto histórico. Por outro lado, ela considera que as preferências dos agentes econômicos resultam de uma espécie de "psicologia universal", e não de uma socialização específica a cada um deles. Ela mobiliza, aliás, como Descartes, uma filosofia da consciência: na teoria da açáo racional, o agente econômico estabelece conscientemente fins explícitos, ele tem intençóes e é determinado por elas. Ela é, por fim, instantaneísta: o mercado supostamente se ajusta instantaneamente e os agentes presumivelmente reagem instantaneamente ao estímulo dos preços. À teoria neoclássica, Bourdieu opóe sua própria abordagem. À hipótese do agente econômico racional (homo economicus) ele opóe a de agentes sociais dotados de um habitus, e à noção de "mercado" utilizada pelos economistas ele opóe o conceito de "campo econômico". Como em seu "curso de sociologia geral", ele evoca a favor dos conceitos de habitus e de campo argumentos que Leibniz desenvolveu em sua discussão da filosofia de Descartes.

Sem deixar de chamar a atenção para as relaçóes entre os dois conceitos, Bourdieu começa por tratar da noçáo de campo. $\mathrm{O}$ curso propóe então estender esta noção ao domínio da economia. É preciso lembrar que Bourdieu havia incialmente elaborado o conceito de campo em uma releitura da sociologia weberiana da religião e em seus trabalhos sobre a literatura na França no século XIX²! Desde a metade dos anos 1970 Bourdieu produziu, paralelamente aos textos que buscavam identificar as "propriedades gerais dos campos”, contribuiçóes que visavam analisar novos

21 BOURDIEU, Pierre. "Gênese e estrutura do campo religioso ". In: BOURDIEU, Pierre. A economia das trocas simbólicas. São Paulo: Perspectiva, 201 I; Idem. As regras da arte. Gênese e estrutura do campo literário. São Paulo, Companhia das Letras, 1996. 
universos (a ciência, o direito, etc.) em termos de campo ${ }^{22}$, cada nova aplicação sendo ocasião de um aprofundamento desta noção. Nos anos 1990, ele evoca várias vezes um projeto de livro, Microcosmos, no qual ele apresentaria uma "teoria geral dos campos"23. Os desenvolvimentos do curso de 1992-1993 sobre o "campo econômico" devem ser compreendidos nesta lógica: na generalização da noção de campo, Bourdieu não poderia ignorar o caso da economia.

Nesse sentido, o curso fornece a ocasião de confrontar as noções de campo e de mercado. Bourdieu começa por ressaltar que a palavra "mercado", geralmente utilizada sem precaução, é muito polissêmica. Ela pode designar realidades muito concretas (o market place, as saídas de um produto), mas também a abstração que os economistas invocam sempre que eles falam, por exemplo, do "mercado puro e perfeito". Bourdieu sublinha que os economistas têm enorme dificuldade em definir a noção de "mercado" que eles tanto utilizam. A existência de um mercado supóe bens intercambiáveis, mas esta simples observação faz com que surja um paradoxo insuperável: ou se considera que dois bens não são jamais perfeitamente substituíveis e o mercado torna-se uma abstração jamais realizada na prática; ou então se considera que todos os bens são potencialmente substitutos de todos os outros e o "mercado" abarca a totalidade da economia.

Bourdieu póe então em prática a estratégia anunciada no começo de seu curso: ele passa em revista algumas "contribuiçóes históricas que a própria teoria econômica traz à crítica da noção de mercado". Ele se refere, por exemplo, a Alfred Marshall, aos teóricos da organização industrial ou ainda aos economistas institucionalistas. Sua abordagem consiste em mostrar que essas diferentes críticas da noção de "mercado", provenientes da ciência econômica, podem ser prolongadas pela aplicaçáo do conceito de "campo". Ele se esforça, portanto, em demonstrar como a noçáo de "campo" pode ser aplicada no caso da economia, mobilizando os desenvolvi-

22 Ver especialmente BOURDIEU, Pierre. "O campo científico ». In: Renato ORTIZ (org.), Bourdieu: sociologia. São Paulo, Olho d’Água, pp. II2-143; Idem, Homo academicus. Florianópolis: Editora da UFSC, 20II; Idem, "A força do direito: elementos para uma sociologia do campo jurídico". In: BOURDIEU, Pierre. O poder simbólico. Rio de Janeiro: Bertrand do Brasil, 1989. pp. 209-254.

23 Bourdieu deixou este livro inacabado. 
mentos gerais que ele havia consagrado ao conceito de campo em cursos (e notadamente no curso de sociologia geral) ou em escritos anteriores. $\mathrm{O}$ campo econômico deve ser pensado ao mesmo tempo como um campo de forças e como um campo de lutas; a estrutura do campo de forças depende do número de concorrentes; o campo é o "lugar de relaçóes de força constantes, permanentes, assim como de mecanismos que tendem a perpetuar estas relaçôes de força”, os dominantes podem exercer poder sobre todos os outros, etc.

Bourdieu faz então uma espécie de parênteses: a utilização do conceito de campo, no caso da economia, mas também de modo mais geral, consiste em enfatizar as relaçóes de concorrência entre os produtores. Quando eles falam de "mercado", os economistas privilegiam as relaçôes entre produtores e consumidores, ou entre uma oferta e uma demanda que se ajustariam pelos mecanismos dos preços. Para Bourdieu, os produtores se determinam em relação aos seus concorrentes antes de se determinar em relação à demanda de consumidores externos. $\mathrm{O}$ campo é então antes de tudo o lugar de uma concorrência entre produtores. Ele destaca que a insistência nas relaçóes entre os produtores já estava presente - com algumas ambiguidades, entretanto - em Max Weber. Essa passagem sobre o conceito de campo como algo que privilegia as relaçôes de concorrência como "conflito indireto" constitui, no interior de seu curso sobre a economia, uma espécie de parênteses que diz respeito à teoria dos campos de modo geral.

Finalmente, Bourdieu propõe uma redefinição da noção de "mercado" com o auxílio do conceito de campo: o mercado seria "uma estrutura de relaçóes de força entre os produtores engajados nas lutas para perpetuar ou transformar estas relaçôes de força”. Nesta perspectiva, não poderíamos ver o mercado como um produto espontâneo e natural da concorrência, ele é "uma construção social". Ao mobilizar sua pesquisa sobre o mercado da casa individual (ou campo de produção da casa individual), Bourdieu insiste ainda no papel da atuação do Estado nesse trabalho de construção, por meio de açóes reguladoras. O Estado ocupa um papel central na concorrência entre os produtores. Embora o discurso liberal goste de opor o mercado e o Estado, Bourdieu demonstra o papel multiforme que o Estado exerce sobre os mercados: o Estado regula os mercados, mantém 
a ordem moral e a confiança, diminui alguns custos, assegura funçóes de homogeneização, de pacificação e de arbitragem, e garante o respeito às regras. O Estado intervém de forma determinante na construção da "oferta" no mercado (por exemplo, ao tomar medidas favoráveis a certas categorias de produtores em detrimento de outras), bem como na construção da "demanda" (que ele pode orientar, por exemplo, por medidas fiscais ou, no caso do mercado da casa individual, por auxílios para a aquisição de uma propriedade). Em suma, o campo de produção econômica aparece como o lugar de uma luta que é em grande medida uma luta pelo poder do Estado.

Nesse estágio do curso Bourdieu tinha pouco tempo. E como ele não queria deixar de falar do habitus, relembra muito brevemente a importância da dimensão simbólica - que ele já havia evocado rapidamente na primeira parte - nas lutas econômicas: o capital econômico está longe de ser o único capital eficiente no campo econômico, onde o capital simbólico também tem por vezes um papel importante. A luta dos produtores pelo monopólio de um mercado pode ter uma forte dimensão simbólica e envolver lutas sobre as classificaçóes e as categorias de percepção do mundo social.

Bourdieu termina tratando da noção de habitus. A respeito deste conceito, ele retoma suas análises anteriormente expostas no Collège de France, em seu curso de sociologia geral em 1982-1983. Ele as apresenta aqui, todavia, na perspectiva de uma discussão da teoria da ação racional mobilizada pela economia neoclássica. Segundo uma observação formulada há muito tempo, essa teoria é antes de tudo normativa. De fato, os economistas não dizem verdadeiramente que os agentes econômicos se comportam de acordo com o modelo de homo economicus: eles pretendem antes dizer como os agentes econômicos se comportariam se agissem de forma racional. Bourdieu, por seu turno, procurou elaborar, com base na noção de habitus, uma teoria da ação que se atentasse à lógica da prática. Desse modo, ele não tem dificuldade em sustentar que o princípio das decisóes dos agentes econômicos (indivíduos, famílias, consumidores, empresas) náo é uma consciência ou um cálculo racional, mas o "habitus". Ele aponta, por exemplo, que mesmo as empresas mais capitalistas raramente confiam em cálculos racionais guiados unicamente pela consideração dos lucros e de sua maximização. 
Bourdieu organiza sua discussão em torno de três grandes alternativas que ele gostaria de superar com a noção de habitus, e das quais a teoria da ação racional se mantém prisioneira. Segundo a estratégia proposta no início do curso, ele cita economistas (por exemplo, Hebert Simon e seu conceito de "racionalidade limitada") que criticaram a teoria da ação racional. A primeira alternativa é a do individual e do coletivo: a teoria da ação racional é uma teoria individualista, ao passo que o habitus representa o "individual coletivizado"; ele é, em cada agente, o produto de uma história coletiva e individual. A segunda alternativa opóe o finalismo, segundo o qual os agentes agem com base em decisóes, ao mecanismo, segundo o qual os agentes são determinados por causas. Bourdieu argumenta que a teoria da ação racional oscila entre essas duas posiçôes que são na verdade equivalentes, uma vez que a decisão racional consiste em agir "com conhecimento de causa”. A noção de habitus, por sua vez, nos leva a considerar que as escolhas são o produto, não de causas ou de decisóes, mas de um senso prático: os trabalhos de psicologia econômica mostram, por exemplo, que as decisóes de compra resultam menos de deliberaçóes racionais ou de cálculos do que de escolhas "razoáveis" operadas pelas crenças. Por fim, a terceira alternativa é a do micro e do macro: a microeconomia neoclássica considera "o macro" como a agregação de ações individuais que seriam feitas por agentes autônomos. O conceito de habitus, por sua vez, leva a considerar agentes que são socializados em condiçóes diferentes, e cujas açóes não poderiam ser agregadas mecanicamente, pois, como são ligados uns aos outros por relaçóes de força, a ação de uns é restringida pela dos outros. Bourdieu termina por destacar que, longe de invalidar sua análise crítica, as aparentes confirmaçóes dos modelos inspirados pela teoria da açáo racional resultam do fato de que, se todos os casos são teoricamente possíveis, os casos mais frequentes são aqueles em que os habitus são globalmente ajustados aos campos nos quais eles se exprimem.

A apresentação que acabo de fazer de Anthropologie Économique é necessariamente parcial: mesmo sem o querer, eu provavelmente dei excessiva ênfase às análises que tratavam diretamente dos meus próprios centros de interesse, e não ressaltei suficientemente as demais. Espero tão-somente ter dado uma visão geral desse curso, e da preocupação de Bourdieu, no início dos anos 1990, de propor uma discussão dos pressupostos da ciência 
econômica na sua forma dominante, e de mostrar como seu próprio sistema conceitual permitia uma outra análise da economia. Nesta perspectiva, o termo "economia" engloba os fatos que nós consideramos espontaneamente como "econômicos", e que constituem os objetos privilegiados da ciência econômica. Todavia, ele engloba também essa "economia de bens simbólicos" que os economistas tendem a excluir de seu domínio de estudo. O curso nos convida a enxergar a economia em um sentido amplo: os economistas veem o "dar e receber" como o único tipo de troca possível (e o comportamento do homo economicus como o único comportamento "racional"), quando na verdade é um tipo de troca particular, criado por um processo histórico particular. Este entendimento mais amplo da noção de "economia" remete à dimensão antropológica do curso, que o título do volume (que não é de Bourdieu) exprime.

Bourdieu deixava normalmente registros escritos de seus cursos e de suas intervençóes orais. Ele o fez parcialmente neste caso: o trabalho de elaboração da noção de "campo econômico" deu origem a um artigo que ele publicou em 1997, antes de retomá-lo em 2000 em As estruturas sociais da economia. Este livro que acrescentava ao artigo uma retomada de outros artigos oriundos da pesquisa sobre a casa individual visava decerto tornar mais visível sua reflexão sobre a economia. A obra ecoa o curso oferecido sete anos antes, e propóe um balanço mais maduro sob certos aspectos: ao colocar por escrito sua reflexão sobre o campo econômico, Bourdieu a aprimora. Mas em outros aspectos ele é mais parcial: o livro As estruturas sociais da economia dá as ferramentas para estudar "os mercados" em uma sociedade capitalista do mesmo modelo que a França no fim do século XX, mas o esforço central no curso de 1992-1993 de elaborar uma "antropologia econômica” passa a segundo plano. Por essas razóes é que o curso publicado sob o título de Antropologia econômica não é nem um "inédito" absoluto, nem um texto totalmente redundante em relação aos textos já disponíveis. Ele tem um valor de complemento, notadamente em relação ao livro As estruturas sociais da economia.

O volume, no entanto, não deve interessar apenas os sociólogos da economia e os economistas. É provável que atraia mais amplamente os sociólogos que se interessam pelo trabalho de Bourdieu, que era um grande 
pesquisador, mas também um grande professor, dotado de qualidades pedagógicas e cujos seminários fomentavam várias ideias. Um dos objetivos dessa série de volumes é compartilhar, senão a experiência que era assistir aos cursos e seminários de Bourdieu, algo que se aproxime disso. Estes cursos, aliás, com suas improvisaçóes parciais e suas hesitaçóes, mostram um Bourdieu em pleno trabalho, mais livre do que em seus escritos, como testemunham, por exemplo, seus breves momentos de humor (é evidente que ele não publicaria esses ensinamentos tais como estáo, ele os teria reescrito minimamente). Os cursos em que Bourdieu une as análises anteriormente publicadas (sempre aprimoradas) e a apresentação, sob uma forma ainda provisória, de seus trabalhos em curso, são também uma entrada interessante nessa teoria sociológica que pode dar a impressão, à primeira vista contraditória, de já ter estado quase que inteiramente presente em suas pesquisas na Argélia, e de não ter cessado de avançar e de se aprofundar ao longo de pesquisas sucessivas.

Sobre este ponto, eu me permito terminar com um comentário um pouco pessoal. No que me concerne, sou particularmente sensível às passagens do curso sobre a noção de "campo econômico". Parece-me, como disse, que aí vemos Bourdieu se confrontar à questáo da extensão do seu conceito à economia, o que eu acho, pessoalmente, muito interessante. Ela não era totalmente evidente: o critério do desinteresse econômico, da autonomia em relação à economia, tinha um papel tão importante nos campos em que ele havia estudado até então (campo literário, jurídico, científico, etc.) que a transposição do conceito à economia não podia se fazer de maneira mecânica. Como sugeri, essa transferência é, ademais, a ocasião para Bourdieu refletir novamente e de maneira geral sobre o conceito de campo. Como sempre, ele se aproveita de um novo caso para lançar luz sobre os aspectos particulares do conceito de campo. Neste contexto, a elaboraçáo da noção de "campo econômico" o conduz aos desenvolvimentos sobre a importância que a questão da concorrência assume entre os produtores. Este ponto náo estava ausente em seus trabalhos sobre os campos de produção cultural, mas nestes ele não constituía, parece-me, uma entrada tão central.

Essa reflexão sobre a noção de "campo econômico" em 1992-1993 talvez tenha influenciado os usos posteriores que Bourdieu fez da noçáo 
de campo. Nos desenvolvimentos sobre a importância das relaçôes de concorrência, me chamou muito a atenção uma rápida alusão ao jornalismo. Ela anuncia, com efeito, as análises que ele desenvolveu nos textos dos anos seguintes. Eu nunca tinha me dado conta, mas é um pouco com base no modelo do "campo econômico" que Bourdieu descreverá o "campo jornalístico" 24: o jornalismo é um espaço de enfrentamento entre empresas dotadas de um peso diferencial e que não são igualmente capazes de impor sua lei aos outros. Eu náo vou desenvolver este ponto; queria táo-somente sugerir que uma leitura possível desses cursos consiste também em seguir as inflexóes sutis que Bourdieu provocou em seus conceitos ao longo do tempo ou, mais exatamente, ao longo de suas pesquisas sucessivas.

24 BOURDIEU, Pierre. Sobre a Televisão, seguido de A influência do jornalismo e Os Jogos Olímpicos. Rio de Janeiro: Zahar, 1997. Os textos de Bourdieu sobre o campo jornalístico começam a aparecer a partir de 1994. 